\title{
APPLICATION OF IMIDAZOLE-BASED IONIC LIQUIDS IN MICROWAVE-ASSISTED EXTRACTION OF TRANS-RESVERATROL FROM GNETUM GNEMON L. SEEDS
}

\author{
ARIF ARRAHMAN ${ }^{1}$, ANDINI GAHAYATI ${ }^{2}$, DEWI RIZKY², SATYA MUSLIMAH ${ }^{2}$, ABDUL MUN'IM ${ }^{2 *}$ \\ ${ }^{1}$ Department of Pharmaceutical-Medicinal Chemistry and Bioanalysis, Faculty of Pharmacy, Universitas Indonesia, Depok, 16424, \\ Indonesia. ${ }^{2}$ Department of Pharmacognosy-Phytochemistry, Faculty of Pharmacy, Universitas Indonesia, Depok, 16424, Indonesia. \\ Email: munim@farmasi.ui.ac.id
}

Received: 04 June 2018, Revised and Accepted: 05 November 2018

ABSTRACT

Objective: This study aimed to compare the efficiency of three imidazole-based ionic liquids (ILs) in the microwave-assisted extraction (MAE) of trans-resveratrol from Gnetum gnemon seeds.

Methods: Trans-resveratrol was quantitatively extracted using 1-hexyl-3-methylimidazolium bromide ([hmim]Br), 1-butyl-3-methylimidazolium chloride $([\mathrm{bmim}] \mathrm{Cl})$, and 1-butyl-3-methylimidazolium tetrafluoroborate $\left(\left[\mathrm{bmim}_{\mathrm{B}} \mathrm{BF}_{4}\right)\right.$ in a microwave oven. Extraction parameters, including solvent concentration, liquid-solid ratio, and extraction time, were optimized using response surface methodology on the basis of the Box-Behnken design. A reverse-phase high-performance liquid chromatography method was used to determine resveratrol content with acetonitrile: water (75:25 v/v) as the mobile phase. The total phenolic content was determined by the Folin-Ciocalteu method.

Results: Under optimal conditions, the resveratrol content when extraction was performed using [hmim] $\mathrm{Br}$, $[\mathrm{bmim}] \mathrm{Cl}$, and $[\mathrm{bmim}] \mathrm{BF}$, was 0.068 , 0.059 , and $0.038 \mathrm{mg} / \mathrm{g}$ dry weight, respectively, and total phenolic content was $0.647,1.736$, and $1.436 \mathrm{mg}$ gallic acid equivalent/g, respectively.

Conclusions: IL-based MAE using [hmim]Br provided the highest trans-resveratrol yield from melinjo seeds and can be used as an alternative method for this purpose.

Keywords: Gnetum gnemon L., Ionic liquid, Melinjo, Microwave-assisted extraction, Response surface methodology, Resveratrol.

(C) 2018 The Authors. Published by Innovare Academic Sciences Pvt Ltd. This is an open access article under the CC BY license (http://creativecommons. org/licenses/by/4. 0/) DOI: http://dx.doi.org/10.22159/ijap.2018.v10s1.09

\section{INTRODUCTION}

Melinjo (Gnetum gnemon L.) is a gymnosperm plant that has pharmacological properties including antibacterial, antiangiogenic, and immunostimulatory properties [1,2]. Melinjo seeds contain chemicals such as tannins, stilbenoids, and flavonoids. Stilbenoids are commonly identified in melinjo seeds including the large stilbenoid derivative resveratrol [3].

Resveratrol is a polyphenolic compound with therapeutic properties including antidiabetic, antioxidant, anticancer, and anti-inflammatory properties [4-6]. Resveratrol can be found in several plant species including red grapes, peanuts, Japan giant knotweed, and melinjo [7-10]. Resveratrol extraction from melinjo is a practical option because it is affordable and quite easy to find.

Several advanced techniques such as supercritical fluid extraction, ultrasonic-assisted extraction, and microwave-assisted extraction (MAE) have been used in attempts to improve the efficiency of extraction methods by minimizing the extraction time and solvent usage while maximizing yield. Although all of these methods have their own requirements, a comparative analysis showed that MAE is faster, uses less material, and requires less solvent $[7,9,11]$.

Resveratrol extraction can be conducted using several conventional solvents. However, some organic solvents may cause problems during the extraction and/or separation of resveratrol from plants due to their toxicity, volatility, and flammability [12]. Therefore, in the present study, we used ionic liquids (ILs) as alternative and safer, environmentally friendly solvents to optimize the process of resveratrol extraction. ILs have shown their potential as extraction solvents for various chemical compounds including flavonoids from Bauhinia championii plants, proanthocyanidins from Larix gmelinii plants, and resveratrol from Polygonum cuspidatum plants [12-14].

We evaluated ILs as alternative solvents in MAE in the present study. Three different imidazole-based ILs, 1-butyl-3-methylimidazolium chloride ([bmim]Cl), 1-butyl-3-methylimidazolium tetrafluoroborate ([bmim] $\mathrm{BF}_{4}$ ), and 1-hexyl-3-methylimidazolium bromide ([hmim]Br), were used to extract trans-resveratrol from G. gnemon seeds by MAE. Chemical structure of ILs is shown in Fig. 1.

The effects of various extraction factors were examined, including IL concentration $(\mathrm{mol} / \mathrm{l})$, solid-liquid ratio $(\mathrm{ml} / \mathrm{g})$, and extraction time (min). Thermal stability is a key parameter for MAE that directly relates to the suitability and long-term stability of extraction media. IL must have sufficient stability to survive the temperature of sample heating [15]. A previous study has reported that imidazolium-based cations exhibit higher thermal stability than tetraalkylammonium cations using thermal gravimetric analysis and differential scanning calorimetry [15]. The anion component was reported to play a key role in the thermal stability of ILs [15].

The IL-MAE method for the extraction of polyphenolic content from G. gnemon seeds was optimized using response surface methodology (RSM). Levels of trans-resveratrol in the extracts were measured using reverse-phase high-performance liquid chromatography (RP-HPLC) with UV detection.

\section{METHODS}

Chemicals and reagents

Gallic acid standard, sodium carbonate, and Folin-Ciocalteu reagent were purchased from Sigma-Aldrich, Germany. Resveratrol standard 
was purchased from Wako, Japan. [bmim]Cl, [hmim]Br, and [bmim] $\mathrm{BF}_{4}$ were purchased from Cheng Jie Chemical Co., Ltd, Shanghai, China. Demineralized water, methanol, HPLC-grade methanol, ethyl acetate, HPLC-grade acetonitrile, and glacial acetic acid were purchased from SmartLab, Indonesia.

\section{Plant materials and sample preparation}

G. gnemon. seeds were collected from Pandeglang, Banten Province, Indonesia (October 2016). The sample was sorted and dried in ovens (Memmert, Germany) at $50-60^{\circ} \mathrm{C}$. The dried sample was powdered using a grinder (Blender Philips HR-2874, Philips, Indonesia) and stored at room temperature until analysis.

\section{Extraction procedure}

\section{$I L-M A E$}

The IL-MAE method was performed as described previously [12]. Briefly, dried and powdered sample (1 g) was soaked in an IL solvent for $1 \mathrm{~h}$ and subjected to MAE (Modena 900 Watt, with slight modification). The extract solution (including any residue) was centrifuged, separated by filtration through a cotton swab, and cooled.

\section{Determination of total phenolic content}

Total phenolic content was determined using a 96-well microplate reader as described previously with some modification [15]. In total, $20 \mu \mathrm{l}$ of sample or standard solution was added to $100 \mu \mathrm{l}$ of $25 \%$ Folin-Ciocalteu solution, homogenized for $1 \mathrm{~min}$, and then let stand for $4 \mathrm{~min}$. Sodium carbonate solution $(75 \mu \mathrm{l})$ was then added, and the solution was homogenized for $1 \mathrm{~min}$. After incubating for $2 \mathrm{~h}$ at room temperature in the dark, absorbance was measured at a wavelength

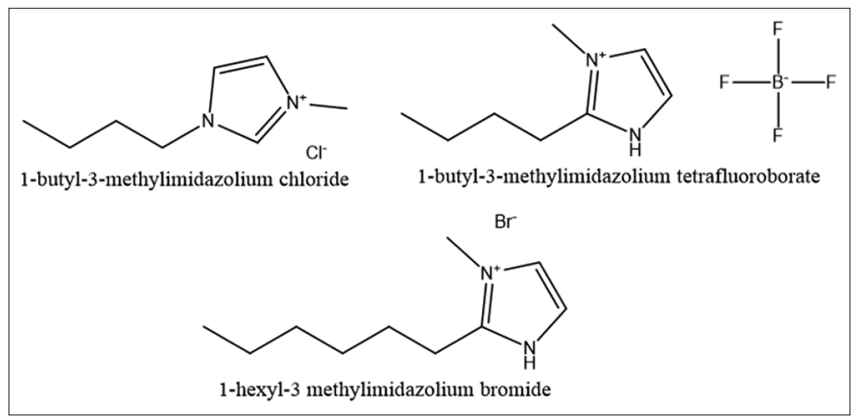

Fig. 1. Chemical structure of ionic liquids of $750 \mathrm{~nm}$ using a 96-well microplate reader (VersaMax ${ }^{\mathrm{TM}}$ ELISA Microplate Reader, USA). Gallic acid solutions (400, 200, 100, 50, and $25 \mu \mathrm{g} / \mathrm{l}$ ) were used as standards. Polyphenol content of extracts (in gallic acid equivalent or GAE) was determined by comparison of sample absorbance with standards. The absorbance of gallic acid standards was measured using the microplate reader running SoftMax 6.5.1 software, and a calibration curve was constructed. The formula for this curve is $y=0.169+0.008 x$. $\mathrm{R}^{2}=0.999$, where $x$ is the total polyphenolic content in GAE and $y$ is the absorbance of either gallic acid standards or samples.

\section{Determination of trans-resveratrol content}

The analytical procedure to determine trans-resveratrol was based on that described in a previous study with slight modification [16]. The HPLC system was a Shimadzu LC-20AT instrument connected to an SPD-20A UV-vis detector, and the column was a Zorbax Eclipse XDB-C18 (150 mm × $4.6 \mathrm{~mm}, 5 \mu \mathrm{m})$. RP-HPLC was performed by isocratic elution at a flow rate of $1 \mathrm{ml} / \mathrm{min}$, using a mobile phase comprising a water-acetonitrile solution (75:25 v/v). The solution was adjusted to $\mathrm{pH} 3.00$ with glacial acetic acid. Samples were filtered through a $0.45-\mu \mathrm{m}$ membrane; then, $20 \mu \mathrm{l}$ of each sample solution was injected. Each sample was injected in duplicate. Absorbance was monitored at $306 \mathrm{~nm}$ to prepare chromatograms. For the quantitation of trans-resveratrol content in samples, a calibration curve was prepared using trans-resveratrol standard solutions ranging from 1 to $15 \mu \mathrm{g} / \mathrm{m}$, and its equation was calculated using LabSolutions software. The formula is $y=33.194+149.376 x . R^{2}=0.999$, where $x$ is the resveratrol yield and $y$ is the peak area of trans-resveratrol standard or sample solutions. Identification of trans-resveratrol in each sample was done by comparing retention times with those of standard peaks (eluting at approximately $8 \mathrm{~min}$ ).

\section{Experimental design using RSM}

Optimization of the IL-MAE method was performed using RSM, which can estimate interactions between factors and process parameters (independent parameters) that affect the trans-resveratrol yield. The experiment was conducted using a Box-Behnken design (three factors and three levels), requiring 17 experiments in total for the optimization of extraction parameters (Table 1). The independent parameters were extraction time (min), liquid-solid ratio (ml/g), and IL concentration $(\mathrm{mol} / \mathrm{l})$, and the outcome was the trans-resveratrol yield. A multilinear quadratic regression model was constructed based on the data from the process parameters as well as the polyphenol content of the extracts using Design-Expert v10 software (Stat-Ease Inc., Minneapolis, MN, USA).

Table 1: Experimental parameters of the Box-Behnken design and resveratrol yield

\begin{tabular}{|c|c|c|c|c|c|c|c|c|c|c|c|c|}
\hline \multirow[t]{2}{*}{ Run } & \multicolumn{4}{|c|}{ [hmim] Br } & \multicolumn{4}{|c|}{ [bmim] Cl } & \multicolumn{4}{|c|}{ [bmim] $\mathrm{BF}_{4}$} \\
\hline & $\begin{array}{l}\mathrm{x}_{1} \\
(\mathrm{~mol} / \mathrm{l})\end{array}$ & $\begin{array}{l}x_{2} \\
(\mathrm{ml} / \mathrm{g})\end{array}$ & $\begin{array}{l}x_{3} \\
(\min )\end{array}$ & y actual (mg/g) & $\begin{array}{l}x_{1} \\
(\mathrm{~mol} / \mathrm{l})\end{array}$ & $\begin{array}{l}\mathrm{x}_{2} \\
(\mathrm{ml} / \mathrm{g})\end{array}$ & $\begin{array}{l}x 3 \\
(\mathrm{~min})\end{array}$ & y actual (mg/g) & $\begin{array}{l}\text { x1 } \\
(\mathrm{mol} / \mathrm{l})\end{array}$ & $\begin{array}{l}\text { x2 } \\
(\mathrm{ml} / \mathrm{g})\end{array}$ & $\begin{array}{l}\text { x3 } \\
(\mathrm{min})\end{array}$ & $y$ actual $(\mathrm{mg} / \mathrm{g})$ \\
\hline 1 & 0.75 & 13 & 15 & 0.025 & 1 & 13 & 10 & 0.042 & 1 & 14 & 15 & 0.037 \\
\hline 2 & 0.5 & 15.5 & 10 & 0.038 & 1.5 & 13 & 12.5 & 0.015 & 1.5 & 13 & 10 & 0.023 \\
\hline 3 & 0.75 & 18 & 15 & 0.027 & 0.5 & 15.5 & 15 & 0.043 & 1.5 & 14 & 12.5 & 0.021 \\
\hline 4 & 1 & 18 & 12.5 & 0.024 & 0.5 & 15.5 & 10 & 0.023 & 1.5 & 14 & 12.5 & 0.021 \\
\hline 5 & 0.75 & 15.5 & 12.5 & 0.033 & 1 & 15.5 & 12.5 & 0.049 & 1.5 & 14 & 12.5 & 0.022 \\
\hline 6 & 1 & 13 & 12.5 & 0.013 & 0.5 & 18 & 12.5 & 0.031 & 1 & 15 & 12.5 & 0.036 \\
\hline 7 & 0.75 & 15.5 & 12.5 & 0.031 & 1 & 15.5 & 12.5 & 0.048 & 1 & 13 & 12.5 & 0.038 \\
\hline 8 & 0.75 & 13 & 10 & 0.016 & 0.5 & 13 & 12.5 & 0.026 & 1.5 & 15 & 15 & 0.018 \\
\hline 9 & 0.75 & 15.5 & 12.5 & 0.038 & 1 & 18 & 10 & 0.011 & 1 & 14 & 10 & 0.033 \\
\hline 10 & 0.75 & 15.5 & 12.5 & 0.023 & 1.5 & 18 & 12.5 & 0.035 & 1.5 & 14 & 12.5 & 0.017 \\
\hline 11 & 1 & 15.5 & 10 & 0.028 & 1 & 18 & 15 & 0.009 & 1.5 & 14 & 12.5 & 0.018 \\
\hline 12 & 0.5 & 15.5 & 15 & 0.068 & 1 & 15.5 & 12.5 & 0.059 & 2 & 13 & 12.5 & 0.013 \\
\hline 13 & 0.5 & 13 & 12.5 & 0.017 & 1.5 & 15.5 & 15 & 0.029 & 2 & 15 & 12.5 & 0.011 \\
\hline 16 & 0.75 & 15.5 & 12.5 & 0.022 & 1.5 & 15.5 & 10 & 0.040 & 2 & 14 & 15 & 0.014 \\
\hline 17 & 1 & 15.5 & 15 & 0.037 & 1 & 15.5 & 12.5 & 0.036 & 1.5 & 15 & 10 & 0.018 \\
\hline
\end{tabular}

$\mathrm{x}_{1}$ : IL concentration (mol/l), $\mathrm{x}_{2}$ : Liquid-solid ratio $(\mathrm{ml} / \mathrm{g}), \mathrm{x}_{3}$ : Extraction time (min), yactual: Trans-resveratrol yield (mg/g) 


\section{RESULTS}

\section{Pre-optimization}

Pre-optimization was conducted to determine the levels of each extraction factor to be included in RSM. There were three extraction factors: IL concentration, extraction time, and liquid-solid ratio. Preoptimization of salts was also conducted to determine the salt type and concentration in the extraction process that resulted in the highest trans-resveratrol yield.

\section{Pre-optimization of IL concentration}

A series of experiments were conducted using different IL concentrations $(0.5,1.0,1.5,2.0$, and $2.5 \mathrm{~mol} / \mathrm{l})$. As shown in Fig. 2, the levels of IL concentration included in RSM were 0.5 and $1.0 \mathrm{~mol} / \mathrm{l}$ for [hmim] Br, 0.5 and $1.5 \mathrm{~mol} / \mathrm{l}$ for $[\mathrm{bmim}] \mathrm{Cl}$, and 1.0 and $2.0 \mathrm{~mol} / \mathrm{l}$ for $[\mathrm{bmim}] \mathrm{BF}_{4}$

\section{Pre-optimization of extraction time}

A series of experiments were conducted using different extraction times $(5,7,10,12$, and $15 \mathrm{~min})$. As shown in Fig. 3, the levels of extraction time included in RSM were 10 and 15 min for [hmim] Br, [bmim] Cl, and $[\mathrm{bmim}] \mathrm{BF}_{4}$

\section{Pre-optimization of liquid-solid ratio}

A series of experiments were conducted using different liquid-solid ratios $(13: 1,15: 1,18: 1,20: 1$, and $23: 1 \mathrm{ml} / \mathrm{g})$. As shown in Fig. 4, the levels of liquid-solid ratios included in RSM were $13: 1$ and 18:1 ml/g

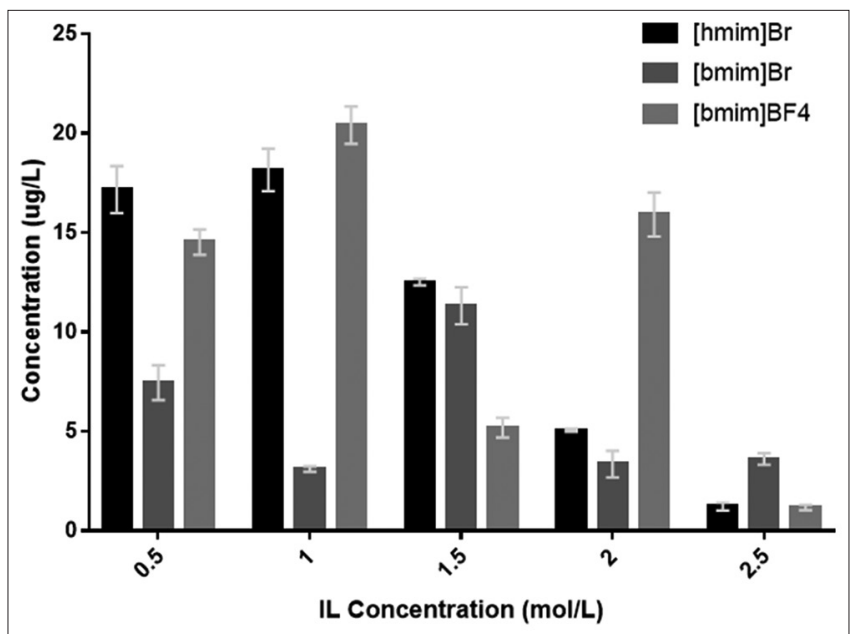

Fig. 2: Pre-optimization of ionic liquid concentration

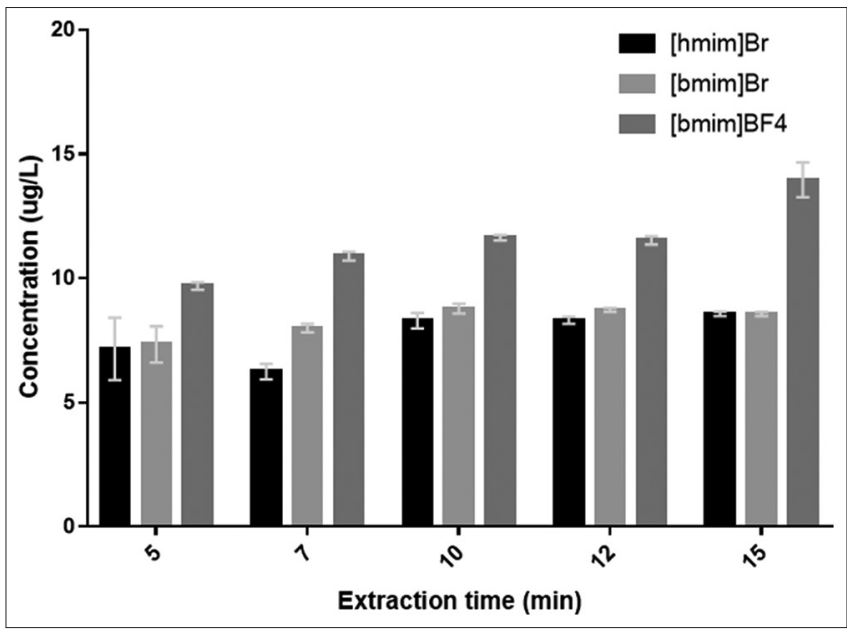

Fig. 3: Pre-optimization of extraction time for [hmim] Br, $13: 1$ and $18: 1 \mathrm{ml} / \mathrm{g}$ for [bmim] Cl, and $13: 1$ and $15: 1 \mathrm{ml} / \mathrm{g}$ for $[\mathrm{bmim}] \mathrm{BF}_{4}$.

\section{Pre-optimization of salt type}

A series of experiments were conducted using different salt types (no salt, $\mathrm{Na}_{2} \mathrm{CO}_{3}, \mathrm{NaCl}$, or $\mathrm{KH}_{2} \mathrm{PO}_{4}$ ). As shown in Fig. 5, the highest yields were obtained using $\mathrm{Na}_{2} \mathrm{CO}_{3}$ for IL extractions with $[\mathrm{hmim}] \mathrm{Br}$ and [bmim] Cl, whereas the highest yields for IL extractions with [bmim] $\mathrm{BF}_{4}$ were obtained using $\mathrm{NaCl}$.

\section{Optimization of the IL-MAE method}

Three factors with three levels (extraction time, IL concentration, and liquid-solid ratio) were optimized using RSM with a Box-Behnken design. The results obtained using Design-Expert v10 software showed the three dimensions of the response surface for the mutual interaction between the factor and process parameters. In total, 17 replicates under different experimental conditions were studied, and the results in terms of trans-resveratrol yield are shown in Table 1.

The highest trans-resveratrol content was obtained using $0.5 \mathrm{~mol} / \mathrm{l}$ [hmim] Br solution, a liquid-solid ratio of $15.5: 1 \mathrm{ml} / \mathrm{g}$, and an extraction time of $15 \mathrm{~min}$. The experimental yield under these conditions using $[\mathrm{hmim}] \mathrm{Br}(0.068 \mathrm{mg} / \mathrm{g})$ was higher than when the same conditions were applied using [bmim] $\mathrm{Cl}(0.059 \mathrm{mg} / \mathrm{g})$ or $\left[\mathrm{bmim}^{\mathrm{B}} \mathrm{BF}_{4}(0.038 \mathrm{mg} / \mathrm{g})\right.$, as shown in Fig. 6.

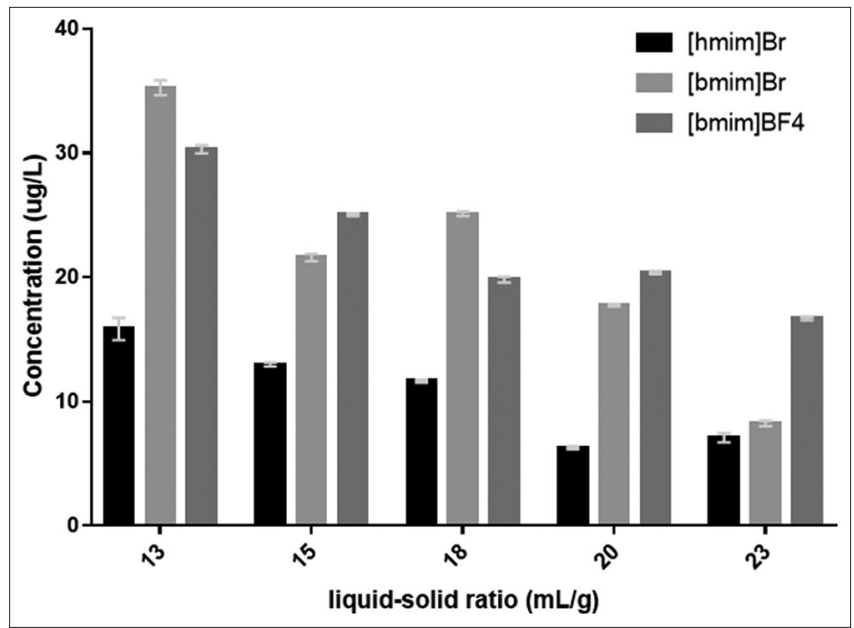

Fig. 4: Pre-optimization of liquid-solid ratio

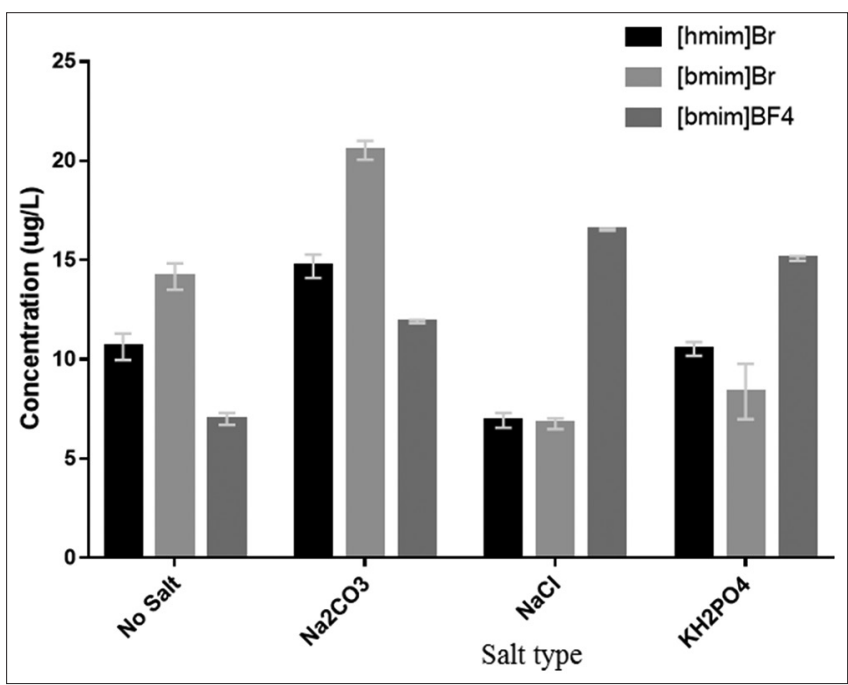

Fig. 5: Pre-optimization of salt type 


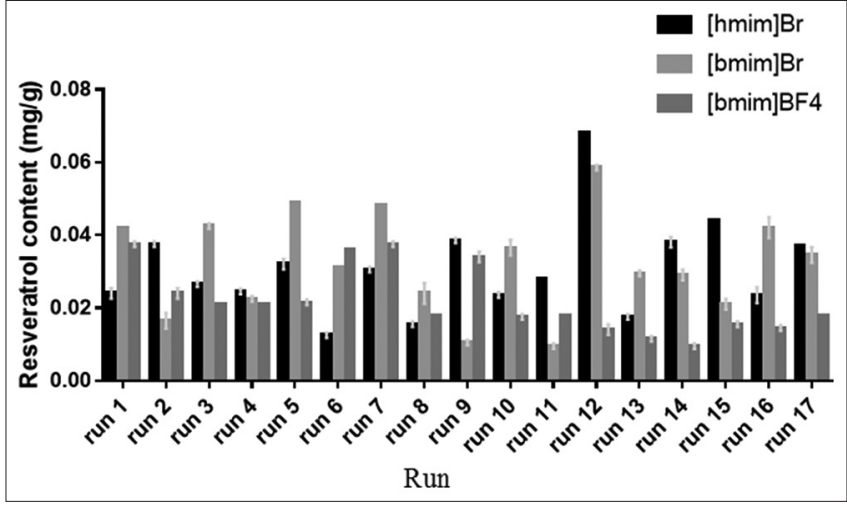

Fig. 6: Highest trans-resveratrol content obtained using the three ionic liquids

Trans-resveratrol yields obtained using [hmim] Br were further analyzed using multivariate regression analysis. The regression model predicting resveratrol yields from $G$. gnemon seeds had the following equation:

$y=0.030-8.111 x_{1}+4.988 x_{2}+7.593 x_{3}-4.991 x_{1} x_{2}-3.902 x_{1} x_{3}-4.751 x_{2} x_{3}+$ $5.534 x_{1}{ }^{2}+7.669 x_{2}{ }^{2}-0.011 x_{3}^{2}$

Where, $y$ is resveratrol content, $x_{1}$ is factor A (IL concentration), $x_{2}$ is factor B (liquid-solid ratio), and $x_{3}$ is factor $\mathrm{C}$ (extraction time). In Table 2, the correlation coefficient $\left(\mathrm{R}^{2}=0.8296\right)$ obtained from the model implied that $>82.96 \%$ of the experimental variation can be explained using this model. Moreover, F-value for lack of fit ( $p>0.05$ ) was 1.71, which implied that the lack of fit was not statistically significant.

\section{HPLC analysis}

Resveratrol was identified in each sample chromatogram, and its retention was compared with that of the standard compound.

\section{Total phenolic content determination}

The Folin-Ciocalteu method with some modifications was used to measure the total polyphenol content in melinjo seed extract. Total phenolic content using the Folin-Ciocalteu method is represented by an equivalent value of GAE. The extraction was performed using MAE to obtain the optimal amount of secondary metabolite. The total polyphenol yields using MAE were 0.647 ([hmim]Br), 1.736 ([bmim]Cl), and $1.436 \mathrm{mg} \mathrm{GAE} / \mathrm{g}\left([\mathrm{bmim}] \mathrm{BF}_{4}\right)$, respectively.

\section{DISCUSSION}

In the present study, ILs including $[\mathrm{hmim}] \mathrm{Br}$, [bmim] $\mathrm{Cl}$, and $[\mathrm{bmim}] \mathrm{BF}_{4}$ were used to extract trans-resveratrol from melinjo seeds. The results show that extraction with $[\mathrm{hmim}] \mathrm{Br}$ resulted in the highest transresveratrol yield; this yield was slightly higher than that obtained with extraction with [bmim]Cl and much higher than that obtained with extraction with $[\mathrm{bmim}] \mathrm{BF}_{4}$. This finding could result from the different interactions of trans-resveratrol with anions used in the ILs. Similar results have been reported in a previous study that showed that ILs containing bromide or chloride as the anion is effective in dissolving trans-resveratrol [13]. Moreover, interactions between the imidazolium cation and trans-resveratrol may also have had a significant role relating to the hydrogen bonding capabilities of ILs.

Extraction parameters influencing the outcome of IL-MAE, including solvent concentration, liquid-solid ratio, and extraction time as independent variables, were optimized to identify the most efficient extraction conditions [14]. The trans-resveratrol yield in each sample was observed as a dependent variable. The results of our study were reported in total polyphenol yields from each sample so as to include other stilbenoid compounds, as previous studies had reported resveratrol dimers in melinjo seeds. Determining the content of each dimer is challenging due to the lack of reference reagents available [1].
Table 2: Analysis of variance for the response surface using a quadratic model for [hmim] Br

\begin{tabular}{llllll}
\hline Source & dF & $\begin{array}{l}\text { Sum of } \\
\text { squares }\end{array}$ & $\begin{array}{l}\text { Mean } \\
\text { square }\end{array}$ & F-value & $\begin{array}{l}\text { p-value } \\
\text { Prob }>\text { F }\end{array}$ \\
\hline Model & 9 & 2.257 & 2.508 & 3.79 & 0.0465 \\
$\mathrm{x}_{1}$ & 1 & 5.263 & 5.263 & 7.95 & 0.0258 \\
$\mathrm{x}_{2}$ & 1 & 1.991 & 1.991 & 3.01 & 0.1265 \\
$\mathrm{x}_{3}$ & 1 & 4.612 & 4.612 & 6.97 & 0.0335 \\
$\mathrm{x}_{1} \times_{2}$ & 1 & 9.964 & 9.964 & 1.50 & 0.2596 \\
$\mathrm{x}_{1} \mathrm{x}_{3}$ & 1 & 6.091 & 6.091 & 0.92 & 0.3695 \\
$\mathrm{x}_{2} \mathrm{x}_{3}$ & 1 & 9.028 & 9.028 & 1.36 & 0.2812 \\
$\mathrm{x}_{1}{ }^{2}$ & 1 & 1.289 & 1.289 & 1.95 & 0.2055 \\
$\mathrm{x}_{2}{ }^{2}$ & 1 & 2.476 & 2.476 & 3.74 & 0.0944 \\
$\mathrm{X}_{3}{ }^{2}$ & 1 & 4.849 & 4.849 & 7.32 & 0.0304 \\
Residual & 7 & 4.635 & 6.621 & & \\
Lack of fit & 3 & 2.606 & 8.685 & 1.71 & 0.3017 \\
Pure error & 4 & 2.029 & 5.074 & & \\
Cor. total & 16 & 2.721 & & & \\
\hline
\end{tabular}

Concentrations of the IL [hmim] Br ranging from 0.5 to $1.0 \mathrm{~mol} / \mathrm{l}$ were used for extraction. The concentration of $0.5 \mathrm{~mol} / \mathrm{l}$ was optimal to obtain the highest trans-resveratrol yields. The effect of IL concentration is related to the viscosity of the IL: The higher its concentration, the more difficult it becomes to attract analytes from the plant matrix [13].

Liquid-solid ratios in the range of $13-18 \mathrm{ml} / \mathrm{g}$ were examined to identify the optimal ratio for extraction. An excessively high or low IL ratio could lead to ineffective extraction. The results show that the highest transresveratrol yields were obtained at a ratio of $15.5 \mathrm{ml} / \mathrm{g}$.

Extraction times ranging from 10 to $15 \mathrm{~min}$ were examined to determine the optimal time of extraction. The optimal time identified in the present study to extract trans-resveratrol with the highest yield was $15 \mathrm{~min}$. This finding indicates that analytes are attracted optimally from the plant matrix within 15 min [15]. The optimal extraction conditions were identified by RSM analysis using Design-Expert v10.03 software. The results show that the optimal IL concentration is $0.5 \mathrm{~mol} / \mathrm{l}$, the optimal liquid-solid ratio is $15.5: 1(\mathrm{ml} / \mathrm{g})$, and the optimal extraction time is $15 \mathrm{~min}$.

\section{CONCLUSIONS}

IL-MAE was applied to extract trans-resveratrol from melinjo seeds. The optimal extraction conditions to maximize trans-resveratrol yield were analyzed using RSM. IL-MAE using [hmim] Br has potential as an alternative method to efficiently extract resveratrol from melinjo seeds.

\section{ACKNOWLEDGMENTS}

The authors acknowledge the Directorate of Research and Humanity Engagement, Universitas Indonesia, for financial support through grant "Hibah PITTA 2017." The authors also thank Prof. Dr. Ibrahim Jantan, M.Sc. of Universiti Kebangsaan, Malaysia, for supervising the work and editing this article.

\section{CONFLICTS OF INTEREST}

All authors declare that they have no conflicts of interest.

\section{REFERENCES}

1. Kato E, Tokunaga Y, Sakan F. Stilbenoids isolated from the seeds of melinjo (Gnetum gnemon L.) and their biological activity. J Agric Food Chem 2009;57:2544-9.

2. Kunimasa K, Ohta T, Tani H, Kato E, Eguchi R, Kaji K, et al. Resveratrol derivative rich melinjo (Gnetum gnemon L.) seed extract suppresses multiple angiogenesis-related endothelial cell functions and tumor angiogenesis. Mol Nutr Food Res 2011;55:1730-4

3. Konno H, Kanai Y, Katagiri M, Watanabe T, Mori A, Ikuta T, et al. 
Melinjo (Gnetum gnemon L.) seed extract decreases serum uric acid levels in nonobese Japanese males: A randomized controlled study. Evid Based Complement Alternat Med 2013;2013:589169.

4. Yao J, Wang JY, Liu L, Li YX, Xun AY, Zeng WS, et al. Anti-oxidant effects of resveratrol on mice with DSS-induced ulcerative colitis. Arch Med Res 2010;41:288-94.

5. Rai G, Mishra S, Suman S, Shukla Y. Resveratrol improves the anticancer effects of doxorubicin in vitro and in vivo models: A mechanistic insight. Phytomedicine 2016;23:233-42.

6. Yu P, Dong L, Zhang Y, Chen W, Xu S, Wang Z, et al. Design, synthesis and biological activity of novel asymmetric C66 analogs as antiinflammatory agents for the treatment of acute lung injury. Eur J Med Chem 2015;94:436-46.

7. Zhang Z, Liu L, Li H, Yao S. Synthesis, characterization, and evaluation of uniformly sized core-shell imprinted microspheres for the separation trans-resveratrol from giant knotweed. Appl Surf Sci 2009;255:9327-32.

8. Zhang Q, Bian Y, Shi Y, Zheng S, Gu X, Zhang D, et al. An economical and efficient technology for the extraction of resveratrol from peanut (Arachis hypogaea) sprouts by multi-stage countercurrent extraction. Food Chem 2015;179:15-25.

9. Routray W, Orsat V. Microwave-assisted extraction of flavonoids: A review. Food Bioprocess Technol 2012;5:409-24
10. Mun'im A, Munadhil MA, Puspitasari N, Azminah R, Yanuar A. Angiotensin converting enzyme inhibitory activity of melinjo (Gnetum gnemon, L.) seed extracts and molecular docking of its stilbene constituents. Asian J Pharm Clin Res 2017;10:243-8.

11. Puli AS, Kumar VK, Regalla VR, Chatterjee A. Microwaveassisted synthesis, characterization, and biological evaluation of phenylacrylamide derivatives of triazoles derived from oxazolones. Asian J Pharm Clin Res 2018;11:285-90.

12. Xu W, Chu K, Li H, Zhang Y, Zheng H, Chen R, et al. Ionic liquidbased microwave-assisted extraction of flavonoids from Bauhinia championii (Benth.) benth. Molecules 2012;17:14323-35.

13. Yang L, Sun X, Yang F, Zhao C, Zhang L, Zu Y. Application of ionic liquids in the microwave-assisted extraction of proanthocyanidins from Larix gmellini Bark. Int J Mol Sci 2012;13:5163-78.

14. Du F, Xiao X, Li G. Application of ionic liquids in the microwaveassisted extraction of trans-resveratrol from rhizoma polygoni cuspidati. J Chromatogr A 2007;1140:56-62.

15. Rostagno M, Prado J. Natural Product Extraction: Principles and Applications. United Kingdom: Royal Society of Chemistry;2013.

16. Souto AA, Carneiro MC, Seferin M, Senna MJ, Conz A, Gobbi K. Determination of trans-resveratrol concentrations in Brazilian red wines by HPLC. J Food Compos Anal 2001;14:441-5. 